Published in final edited form as:

Angew Chem Int Ed Engl. 2012 June 18; 51(25): 6121-6125. doi:10.1002/anie.201109156.

\title{
Biomimetic Surface Engineering of Lanthanide-Doped Upconversion Nanoparticles as Versatile Bioprobes
}

\author{
Dr. Le-Le Li, \\ Department of Chemistry, Beckman Institute for Advanced Science and Technology, University of \\ Illinois at Urbana-Champaign, 600 S. Mathews Avenue, Urbana, IL 61801 (USA)

\section{Dr. Ruobing Zhang,} \\ Department of Physics, Center for the Physics of Living Cells, University of Illinois at Urbana- \\ Champaign, 1110 W. Green Street, Urbana, IL 61801 (USA)

\section{Dr. Leilei Yin,} \\ Department of Chemistry, Beckman Institute for Advanced Science and Technology, University of \\ Illinois at Urbana-Champaign, 600 S. Mathews Avenue, Urbana, IL 61801 (USA)

\section{Kezhi Zheng,} \\ State Key Laboratory on Integrated Optoelectronics, College of Electronic Science and \\ Engineering, Jilin University, Changchun 130012 (P. R. China)
}

\section{Prof. Dr. Weiping Qin,}

State Key Laboratory on Integrated Optoelectronics, College of Electronic Science and Engineering, Jilin University, Changchun 130012 (P. R. China)

Prof. Dr. Paul R. Selvin, and

Department of Physics, Center for the Physics of Living Cells, University of Illinois at UrbanaChampaign, 1110 W. Green Street, Urbana, IL 61801 (USA)

\section{Prof. Dr. Yi Lu}

Department of Chemistry, Beckman Institute for Advanced Science and Technology, University of Illinois at Urbana-Champaign, 600 S. Mathews Avenue, Urbana, IL 61801 (USA); Fax:

(+1)217-244-3186

Yi Lu: yi-lu@illinois.edu

\section{Abstract}

A general and versatile biomimetic approach to synthesize water dispersible and functionalizable upconverting nanoparticles (UCNPs) for selective imaging of live cancer cells is reported. The approach involves coating the surface of UCNPs with a monolayer of phospholipids containing different functional groups, allowing for conjugation of many molecules for a wide range of applications in fields such as bioinspired nanoassembly, biosensing, and bio-medicine.

\section{Keywords}

Upconverting nanoparticles; surface engineering; functionalizable; bioapplication

\footnotetext{
Correspondence to: Yi Lu, yi-lu@illinois.edu.

Homepage: http://www.chemistry.illinois.edu/faculty/Yi_Lu.html

Supporting information for this article is available on the WWW under http://www.angewandte.org or from the author.
} 
The past decade has witnessed an explosion of interest in the development of luminescent nanoparticles because of their excellent potentials in biomedical application. ${ }^{[1]}$ Most recently, lanthanide ion doped upconversion nanoparticles (UCNPs), typically $\mathrm{NaMF}_{4}: \mathrm{Yb}^{3+}$ / $\mathrm{Ln}^{3+}(\mathrm{M}=\mathrm{Y}$ or $\mathrm{Gd}, \mathrm{Ln}=\mathrm{Er}$ or $\mathrm{Tm})$, has become as an exciting new class of nanophosphors that convert near infrared (NIR) excitation light (typically $\sim 980 \mathrm{~nm}$ ) into shorter wavelength luminescence. ${ }^{[2,3]}$ The major appeal of UCNPs for bioimaging is that it can achieve deeper tissue penetration as well as higher-contrast optical imaging due to its ability to suppress autofluorescence and minimize photodamage to living cells. ${ }^{[3-5]}$ Furthermore, UCNPs can afford tunable multicolor emission with exceptional photostability. These properties coupled with low toxicity to cells make UCNPs an ideal choice for long-term in vitro and in vivo imaging. ${ }^{[3-5]}$

Despite these promises, a major challenge in the field of UCNPs is lack of a general methodology to make water-dispersible, bio-compatible and functionalizable UCNPs, as they are normally prepared in organic solvents and capped with hydrophobic ligand that lacks any functional groups for surface modification; meeting this challenge is a prerequisite for many biomedical application of this class of materials. ${ }^{[3-5]}$ Toward this goal, silica coating has been developed to render them dispersible in water, but further surface modification steps are still required to attach functional groups on silica shell for bioconjugation. Oxidation of the capped oleic acid ligands to azelaic acid could make UCNPs both water dispersible and functionalizable, ${ }^{[4 c]}$ but the oxidation process produces adventitious $\mathrm{MnO}_{2}$ that can quench the luminescence. ${ }^{[4 \mathrm{~d}]}$ Despite the recent advances in the direct synthesis of water dispersible UCNPs, ${ }^{[4 \mathrm{~b}]}$ and postsynthesis ligand oxidation with ozone $^{[4 \mathrm{q}]}$ or ligand-free treatments ${ }^{[4 \mathrm{r}]}$ to render them water dispersible and functionalizable, there is a need for a simple and general method for producing biocompatible UCNPs with flexible surface chemistry for coupling of various biomolecules capable of application as diverse as targeted imaging or sensing of live biological processes, therapeutics, and photovoltaics. ${ }^{[3 \mathrm{a}, \mathrm{f}]}$ Herein, we report such a approach to engineer the UCNPs surface coating with a monolayer of functional phospholipids (Figure 1). These phospholipids afford biocompatibility by mimicking the composition and functionality of the cell's external membrane.

Phospholipid is a major component of all cell membranes that possess special amphiphilic structure and excellent biocompatible properties. Phospholipids-based nanostructures (e.g. liposomes) have been widely used for encapsulating and delivering drugs to numerous cell lines, and have been approved by the US Food and Drug Administration for disease treatment in the clinic. ${ }^{[6]}$ Because of their intriguing properties, phospholipids have been successively used to provide biofunctionality to various inorganic nanoparticles such as QDs, ${ }^{[7]}$ iron naniparticles, ${ }^{[8]}$ and mesoporous silica nanoparticles ${ }^{[9]}$ for different biomedical applications. Here we try to employ phospholipids engineering to overcome one of the biggest challenge in UCNPs areas mentioned above. As shown in Figure 1, the phospholipids designed contain four segments: two fatty acid chains, a phosphate group, a polyethylene glycol (PEG) segment, and a functional group to realize the biomimetic surface engineering of UCNPs. The UCNPs would become water-dispersible driven by the hydrophobic van der Waals interactions between the hydrophobic tail of the phospholipids and the primary oleate ligands on the UCNPs surface. The fatty acid chains of the phospholipids are embedded in the hydrophobic surface of the UCNPs, while the hydrophilic part points out toward the aqueous environment. In such a way, UCNPs can be surface-modified with PEG, an inert, nontoxic, and nonimmunogenic hydrophilic polymer. Furthermore, various functional groups (e.g. carboxyl, amine, maleimide, biotin) at the end of the PEG of the Lipo-UCNPs can be easily conjugated with various biomolecules for specific biomedical applications. 
Highly efficient upconverting $\mathrm{NaYF}_{4}: 18 \% \mathrm{Yb} / 2 \%$ Er nanoparticles was synthesized according to the literature methods using oleic acid as the stabilizing agent. ${ }^{[10]}$ As shown in Figure 2a, these nanocrystals display uniform hexagonal plate-like morphology with mean sizes of $\sim 60 \mathrm{~nm}$ and high crystallinity. To demonstrate the feasibility of the method described in Figure 1, a PEGylated phospholipid, 1,2-distearoyl-sn-glycero-3phosphoethanolamine-N-[carboxy(polyethylene gly-col)-2000] (DSPE-PEG-COOH), was used to coat the above UCNPs. Representative TEM images (Figure 2b, Figure S1) of the resulting Lipo-UCNPs show that they remain monodisperse in size without obvious shape change and aggregation. High-resolution TEM investigation (Figure 2b, inset) confirms the core/shell crystallized nanocrystals with uniform $\sim 2 \mathrm{~nm}$ thick hydrophobic oleic acid/lipids layer around the surface. Dynamic light scattering (DLS) measurements indicated that the Lipo-UCNPs were well dispersed in water with a mean hydrodynamic diameter of $\sim 88 \mathrm{~nm}$ (Figure S2). In comparison with oleic UCNPs dispersed in cyclohexane $(\sim 66 \mathrm{~nm})$, this $\sim 22$ $\mathrm{nm}$ increase in diameter is in agreement with a monolayer of the PEGylated phospholipids.

The DSPE-PEG-COOH coated Lipo-UCNPs possess excellent water-solubility by virtue of their cloaks of hydrated PEG molecules (Figure 3a). Upon continuous excitation at $980 \mathrm{~nm}$, the luminescence of the lipids coated $\mathrm{NaYF}_{4}: \mathrm{Yb} / \mathrm{Er}$ in water appears predominantly green in color (Figure 3a). The corresponding upconversion luminescence spectrum of Lipo-UCNPs in water is similar to that of the as-prepared samples in cyclohexane with a slight decrease in relative integrated green/red emission ratio due to the surface quenching effect of water molecules (Figure 3b). ${ }^{[5 b]}$ These results strongly indicate that the characteristic upconversion property of the nanoparticles was unaffected by the phospholipid coating. The NIR-to-visible upconverting property of the Lipo-UCNPs was further investigated at single molecule level. Immobilized individual Lipo-UCNPs were imaged with excitation at 980 $\mathrm{nm}$, showing bright individual green spots on the coverslip surface (Figure $3 \mathrm{c}$ ). These LipoUCNPs spots exhibited neither blinking nor photobleaching over 30 min continuous laser excitation (Figure 3d). Figure S3 shows the point spread functions (PSF) of a few single Lipo-UCNP luminescent spots excited at $980 \mathrm{~nm}, 50 \mathrm{~kW} / \mathrm{cm}^{2}$. At $30 \mathrm{~ms}$ exposure time, we detected $\sim 6000$ photons from one single spot, allowing us to localize the center of the spot to $1.6 \mathrm{~nm}$ accuracy. These properties make the Lipo-UCNP an excellent probe for single molecule imaging. ${ }^{[11]}$ Furthermore, the Lipo-UCNPs showed long-term stability in water and resistance to aggregation over an extended period of several months (Figure S4).

To take advantage of the wide availability of the phospholipids with various headgroups, we then investigated the versatility of our method in preparing Lipo-UCNPs with different functional groups, which then allow attachment of a wide range of molecules on the surface. As shown in Figure S5, organic dye functionalized Lipo-UCNPs could be synthesized through this one-step assembly by using a dye-labeled phospholipid. A Förster resonance energy transfer (FRET) between the dye and UCNPs was observed; such a system may represent a versatile hybrid probe to study FRET in fundamental and biological processes. In addition, to explore the functionalization of Lipo-UCNPs with biomolecules, we performed bioconjugation of DNA on the $\mathrm{NaYF}_{4}$ : $\mathrm{Yb} / \mathrm{Er} \mathrm{UCNPs}$ by replacing DSPE-PEG-COOH phospholipids with a mixture of DSPE-PEG and DSPE-PEG-Maleimide (1:1) for the UCNPs coating to introduce a primary maleimide to the outer surface of the Lipo-UCNPs. Thiol-modified DNA was then covalently attached to the Lipo-UCNPs through the sulfhydryl-maleimide coupling reaction. Such a reaction was confirmed by the observation of typical absorbance of DNA at $260 \mathrm{~nm}$ after the conjugation (Figure S6). To test the functionality of the DNA on the Lipo-UCNPs, these nanoparticles were then incubated with $5 \mathrm{~nm}$ gold nanoparticles (AuNPs) that was modified with thiolated complementary DNA (cDNA). As shown in Figure 4 and Figure S7, Lipo-UCNPs was surrounded by a number of AuNPs, forming the satellite nanostructure. As a control, the assembly of the nanoparticles was not observed when AuNPs was functionalized with noncomplementary DNA (Figure 
S7), indicating that DNA molecules not only were functionalized to Lipo-UCNPs in a large number but also retained their specific hybridization to its complementary DNA target. The UV/Vis spectrum of the DNA-directed Lipo-UCNP-AuNPs nanoassemblies shows a broad absorption band around $520 \mathrm{~nm}$ (Figure S8), consistent with the plasmon resonance frequencies observed in similar AuNPs. Interestingly, minimal gold-induced luminescence quenching was observed (Figure S9), suggesting that the phospholipids/DNA layer prevented the contact between the UCNP and the AuNPs. ${ }^{[12]}$ Owing to its high sequence specificity and addressability, DNA has recently attracted great attention as a promising building blocks for biosensing, nanomedicine, and assembly of nanoparticles. ${ }^{[13]}$ The versatile conjugation of DNA on UCNPs reported here will thus be beneficial.

Having demonstrated the general and versatile method to prepare functionalizable LipoUCNPs, we then explored the usage of the Lipo-UCNPs for targeted imaging of cancer cells. Because folate can bind to overexpressed folate receptors on several cancer cell lines, DSPE-PEG-Folate was mixed with DSPE-PEG (1:9) and used for the $\mathrm{NaYF}_{4}: \mathrm{Yb} / \mathrm{Er}$ coating to introduce the targeting folate ligand on the surface of Lipo-UCNPs (Figure 5a). The HeLa cells treated with the resulting Lipo-UCNPs-FA were then imaged with widefield or multipoint matrix scan excitation by an NIR laser. ${ }^{[11 \mathrm{c}]}$ The HeLa cells exposed to LipoUCNPs-FA showed many luminescent spots within the cell cytoplasm, indicating excellent binding and internalization of nanoparticles into the cancer cells (Figure 5b). The cellular uptake of the nanoparticles was further confirmed by the 3D reconstruction movie from the data of 3D scan imaging, showing that the Lipo-UCNPs were distributed mainly inside the cells (see Figure S10 and Movie S1). These results are consistent with the projected receptor-mediated endocytosis mechanism. In contrast, the Lipo-UCNPs without the exterior folate ligands incubated with HeLa cells under the same physiological conditions showed minimum uptake of the nanoparticles in the live cells (Figure 5c), confirming the role of the folate ligand in cell targeting. The availability of various cancer-cell targeting ligands and the ease of conjugating them with the Lipo-UCNPs, as well as their unique optical properties, make the Lipo-UCNPs promising nanoprobes for targeted imaging of cancer cells.

In conclusion, a universal and generalized method has been developed for the synthesis of UCNPs with flexible surface chemistry for a wide range of applications. The approach has several significant advantages. First, the biomimetic surface offers water-soluble and biocompatible UCNPs, which as demonstrated by PEGylated liposomes could afford nanoparticles prolonged circulation half-life, reduced nonspecific binding, and prevention of the reticuloendothelial system. ${ }^{[14]}$ Second, wide commercial available lipids with various headgroups (e.g. $\mathrm{COOH}, \mathrm{NH}_{2}, \mathrm{SH}$, maleimide, biotin, cyanur chloride) at the end allows for ease functionalization of UCNPs and thus wide applications of bioconjugated UCNPs. Third, the method provides a way to fine-tune the surface physical properties of UCNPs to be positive, negative, or zwitterionic by simply using the lipids with different charged headgroups. Forth, the method can be used for construction of multifunctional materials. For example, dye-labled lipids enable the design of FRET systems on UCNPs; paramagnetic gadolinium (III) complex modified lipids will allow for the synthesis of UCNPs-based nanoprobes for both upconversion luminescence imaging and magnetic resonance imaging (MRI). Fianlly, this lipid-coating procedure is also generally applicable to other UCNPs with different size. Hydrophobic UCNPs with size of $\sim 6 \mathrm{~nm}$ and $\sim 130 \mathrm{~nm}$ have also been demonstrated to be functionalized with phospholipids monolayer (Figure S11 and S12). Therefore, the approach demonstrated here will make it possible for much wider applications of UCNPs. 


\section{Acknowledgments}

This work was supported by the Beckman Institute of the University of Illinois through a Seed Grant, and the US National Science Foundation (CMMI 0749028 and DMR-0117792 to YL, 0968976 and 082265 to PS) and National Institute of Health (AR044420 to PS).

\section{References}

1. a) Gao X, Cui Y, Levenson RM, Chung LWK, Nie S. Nat Biotechnol. 2004; 22:969-976. [PubMed: 15258594] b) Chan WCW, Nie S. Science. 1998; 281:2016-2018. [PubMed: 9748158] c) Bruchez M, Moronne M, Gin P, Weiss S, Alivisatos AP. Science. 1998; 281:2013-2016. [PubMed: 9748157] d) Xia Y, Li W, Cobley CM, Chen J, Xia X, Zhang Q, Yang M, Cho EC, Brown PK. Acc Chem Res. 2011; 44:914-924. [PubMed: 21528889]

2. a) Denk W, Strickler J, Webb WW. Science. 1990; 248:73-76. [PubMed: 2321027] b) Heer S, Kömpe K, Güdel HU, Hasse M. Adv Mater. 2004; 16:2102-2105.

3. a) Wang F, Liu X. Chem Soc Rev. 2009; 38:976-989. [PubMed: 19421576] b) Haase M, Schäfer H. Angew Chem Int Ed. 2011; 50:5808-5829.c) Auzel F. Chem Rev. 2003; 104:139-174. [PubMed: 14719973] d) Feng W, Sun L, Zhang Y, Yan C. Coord Chem Rev. 2010; 254:1038-1053.e) Wang G, Peng Q, Li Y. Acc Chem Res. 2011; 44:322-332. [PubMed: 21395256] f) Mader HS, Kele P, Saleh SM, Wolfbeis OS. Curr Opin Chem Biol. 2010; 14:582-596. [PubMed: 20829098]

4. a) Wang J, Wang F, Wang C, Liu Z, Liu X. Angew Chem Int Ed. 2011; 50:10369-10372.b) Wang F, Liu X. J Am Chem Soc. 2008; 130:5642-5643. [PubMed: 18393419] c) Chen ZG, Chen HL, Hu H, Yu MX, Li FY, Zhang Q, Zhou ZG, Yi T, Huang CH. J Am Chem Soc. 2008; 130:3023-3029. [PubMed: 18278910] d) Naccache R, Vetrone F, Mahalingam V, Cuccia LA, Capobianco JA. Chem Mater. 2009; 21:717-723.e) Wu S, Han G, Milliron DJ, Aloni S, Altoe V, Ta-lapin DV, Cohen BE, Schuck PJ. Proc Natl Acad Sci USA. 2009; 106:10917-10921. [PubMed: 19541601] f) Li Z, Zhang Y. Angew Chem Int Ed. 2006; 45:7732-7735.g) Wang M, Mi C, Wang W, Liu C, Wu Y, Xu Z, Mao C, Xu S. ACS Nano. 2009; 3:1580-1586. [PubMed: 19476317] h) Yu M, Li F, Chen Z, Hu H, Zhan C, Huang C. Anal Chem. 2009; 81:930-935. [PubMed: 19125565] i) Nyk M, Kumar R, Ohulchanskyy TY, Bergey EJ, Prasad PN. Nano Lett. 2008; 8:3834-3838. [PubMed: 18928324] j) Zhang F, Braun GB, Shi Y, Zhang Y, Sun X, Reich N, Zhao D, Stucky G. J Am Chem Soc. 2010; 132:2850-2851. [PubMed: 20158187] k) Ye X, Collins J, Kang Y, Chen J, Chen DTN, Yodh AG, Murray CB. Proc Natl Acad Sci USA. 2010; 107:22430-22435. [PubMed: 21148771] 1) Wang C, Cheng L, Liu Z. Biomaterials. 2011; 32:1110-1120. [PubMed: 20965564] m) Zhang H, Li Y, Ivanov IA, Qu Y, Huang Y, Duan X. Angew Chem Int Ed. 2010; 49:2865-2868.n) Carling CJ, Nourmo-hammadian F, Boyer JC, Branda NR. Angew Chem Int Ed. 2010; 49:3782-3785.o) Fischer LH, Harms GS, Wolfbeis OS. Angew Chem Int Ed. 2011; 50:4546-4551.p) Tu D, Liu L, Ju Q, Liu Y, Zhu H, Li R, Chen X. Angew Chem Int Ed. 2011; 50:6306-6310.q) Zhou H, Xu C, Sun W, Yan C. Adv Funct Mater. 2009; 19:3892-3900.r) Bogdan N, Vetrone F, Ozin GA, Capobianco JA. Nano Lett. 2011; 11:835-840. [PubMed: 21244089]

5. (a) Wang F, Han Y, Lim CS, Lu YH, Wang J, Xu J, Chen HY, Zhang C, Hong M, Liu X. Nature. 2010; 463:1061-1065. [PubMed: 20182508] b) Wang F, Wang J, Liu X. Angew Chem Int Ed. 2010; 49:7456-7460.c) Mai H, Zhang Y, Si R, Yan Z, Sun L, You L, Yan C. J Am Chem Soc. 2006; 128:6426-6436. [PubMed: 16683808] d) Abel KA, Boyer JC, van Veggel FCJM. J Am Chem Soc. 2009; 131:14644-14645. [PubMed: 19824725] e) Wang F, Deng R, Wang J, Wang Q, Han Y, Zhu H, Chen X, Liu X. Nat Mater. 2011:968-973. [PubMed: 22019945] f) Schäfer H, Ptacek P, Kömpe K, Hasse M. Chem Mater. 2007; 19:1396-1400.

6. a) Ferrara KW, Borden MA, Zhang H. Acc Chem Res. 2009; 42:881-892. [PubMed: 19552457] b) Al-Jamal W, Kostarelos K. Acc Chem Res. 2011; 44:1094-1104. [PubMed: 21812415] c) Wagner A, Platzgummer M, Kreismayr G, Quendler H, Stiegler G, Ferko B, Vecera G, Vorauer-Uhl K, Katinger H. J Liposome Res. 2006; 16:311-319. [PubMed: 16952884]

7. a) Dubertret B, Skourides P, Norris DJ, Noireaux V, Brivanlou AH, Libchaber A. Science. 2002; 298:1759-1762. [PubMed: 12459582] b) Carion O, Mahler B, Pons T, Dubertret B. Nat Protoc. 2007; 2:2383-2390. [PubMed: 17947980] c) Kim S, Shim W, Seo H, Bae JH, Sung J, Choi SH, Moon WK, Lee G, Lee B, Kim SW. Chem Commun. 2009:1267-1269. 
8. a) Shtykova EV, Huang X, Remmes N, Baxter D, Stein B, Dragnea B, Svergun DI, Bronstein LM. J Phys Chem C. 2007; 111:18078-18086.b) Xie J, Peng S, Brower N, Pourmand N, Wang SX, Sun S. Pure Appl Chem. 2006; 78:1003-1014.c) Namiki Y, Namiki T, Yoshida H, Ishii Y, Tsubota A,

Koido S, Nariai K, Mitsunaga M, Yanagisawa S, Kashiwagi H, et al. Nat Nanotechnol. 2009; 4:598-606. [PubMed: 19734934]

9. Ashley CE, Carnes EC, Phillips GK, Padilla D, Durfee PN, Brown PA, Hanna TN, Liu J, Phillips B, Carter MB, et al. Nat Mater. 2011; 10:389-397. [PubMed: 21499315]

10. Li ZQ, Zhang Y. Nanotechnology. 2008; 19:345606. [PubMed: 21730655]

11. a) Yildiz A, Forkey JN, McKinney SA, Ha T, Goldman YE, Selvin PR. Science. 2003; 300:20612065. [PubMed: 12791999] b) Thompson RE, Larson DR, Webb WW. Biophys J. 2002; 82:27752783. [PubMed: 11964263] c) Zhang R, Rothenberg E, Fruhwirth G, Simonson PD, Ye F, Golding I, Ng T, Lopes W, Selvin PR. Nano Lett. 2011; 11:4074-4078. [PubMed: 21882883]

12. Jin Y, Gao X. Nat Nanotechnol. 2009; 4:571-576. [PubMed: 19734929]

13. a) Liu J, Cao Z, Lu Y. Chem Rev. 2009; 109:1948-1998. [PubMed: 19301873] b) Tan SJ, Campolongo MJ, Luo D, Cheng W. Nat Nanotech. 2011; 6:268-276.c) Park SY, Lytton-Jean AKR, Lee B, Weigand S, Schatz GC, Mirkin CA. Nature. 2008; 451:553-556. [PubMed: 18235497]

14. a) Drummond DC, Meyer O, Hong K, Kirpotin DB, Papahadjopoulos D. Pharm Rev. 1999; 51:691-743. [PubMed: 10581328] b) Drummond DC, Zignani M, Leroux JC. Prog Lipid Res. 2000; 39:409-460. [PubMed: 11082506] 


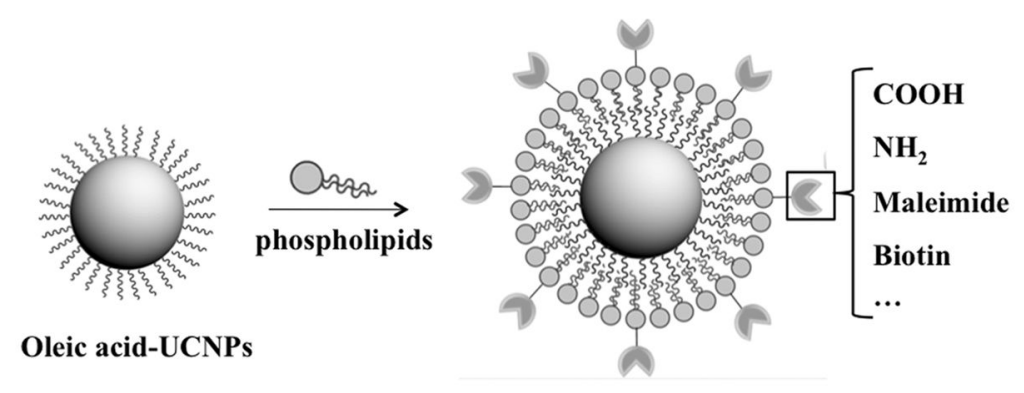

Lipo-UCNPs

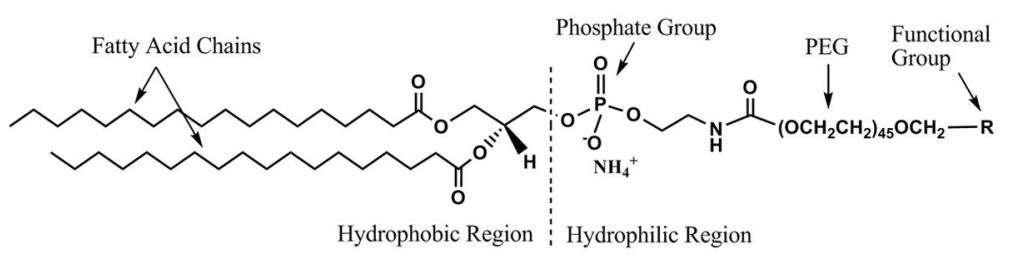

Figure 1.

Schematic illustration of the assembling of the water dispersible and functionalizable UCNPs by biomimetic engineering the oleic acid capped UCNPs with a monolayer of phospholipids. Bottom shows the molecular structure of the designed phospholipid. 


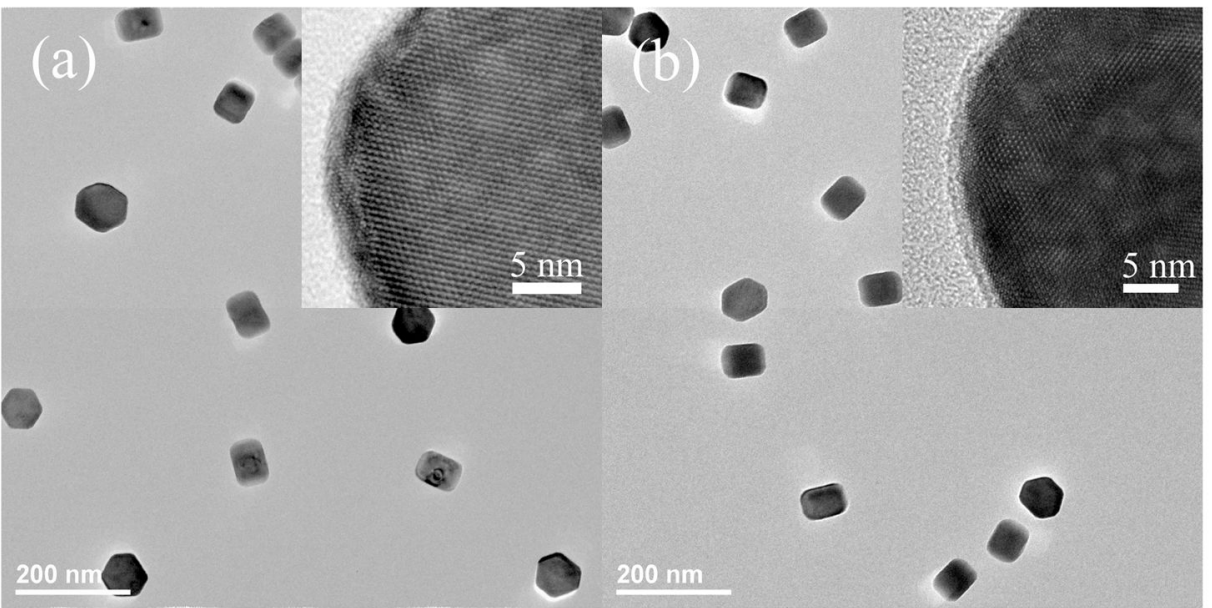

Figure 2.

TEM images of the (a) as-prepared and (b) phospholipids DSPE-PEG-COOH coated UCNPs. Inset shows the high-resolution TEM image of the respective sample. 

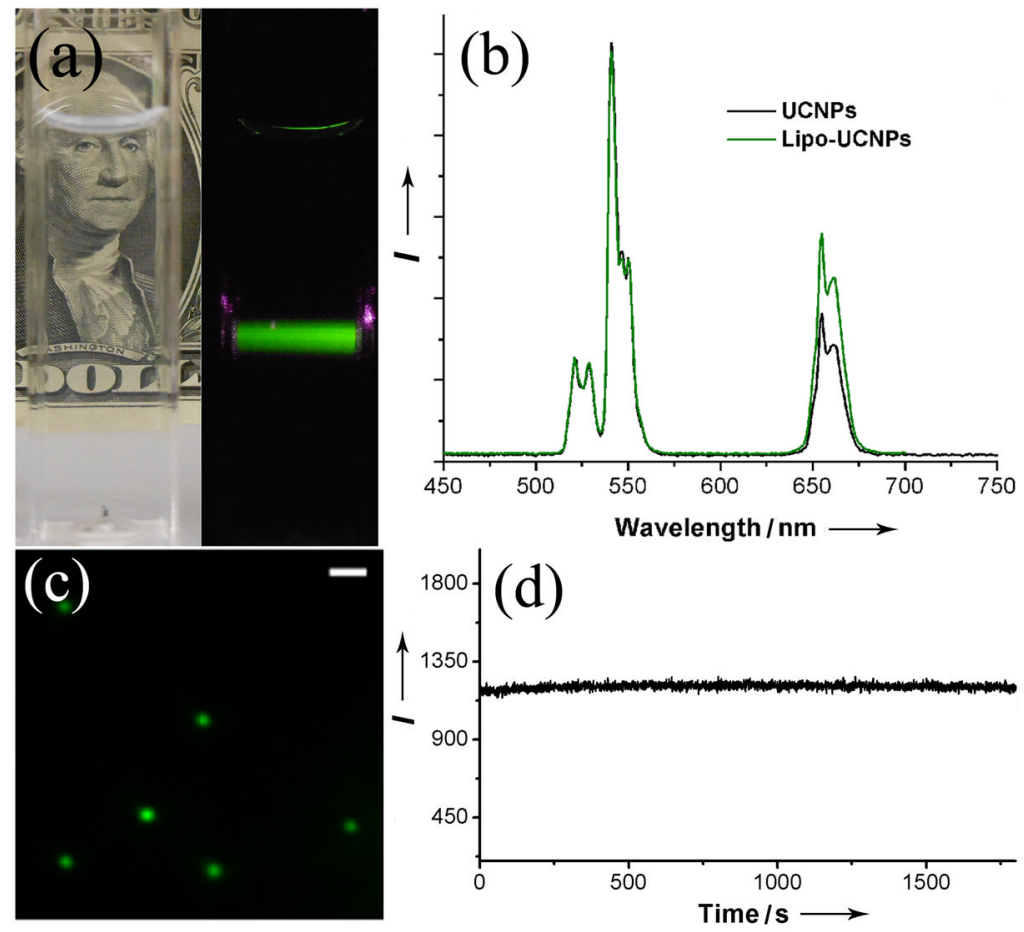

Figure 3.

(a) Photographs of the transparent water solution of Lipo-UCNPs without laser illumination (left) and the upconverted visible luminescence under continuous-wave $980 \mathrm{~nm}$ laser illumination (right). (b) Room-temperature upconversion luminescence spectra of asprepared UCNPs in cyclohexane and Lipo-UCNPs in water under excitation at $980 \mathrm{~nm}$. (c) Upconverted luminescent image of individual Lipo-UCNPs attached to a coverslip under $980 \mathrm{~nm}$ excitation. Scale bar $=1 \mu \mathrm{m}$. (d) Super photostability of a single Lipo-UCNP. Emission collected at 510-560 $\mathrm{nm}$ channel. Exposure time $=0.5 \mathrm{~s}$. 

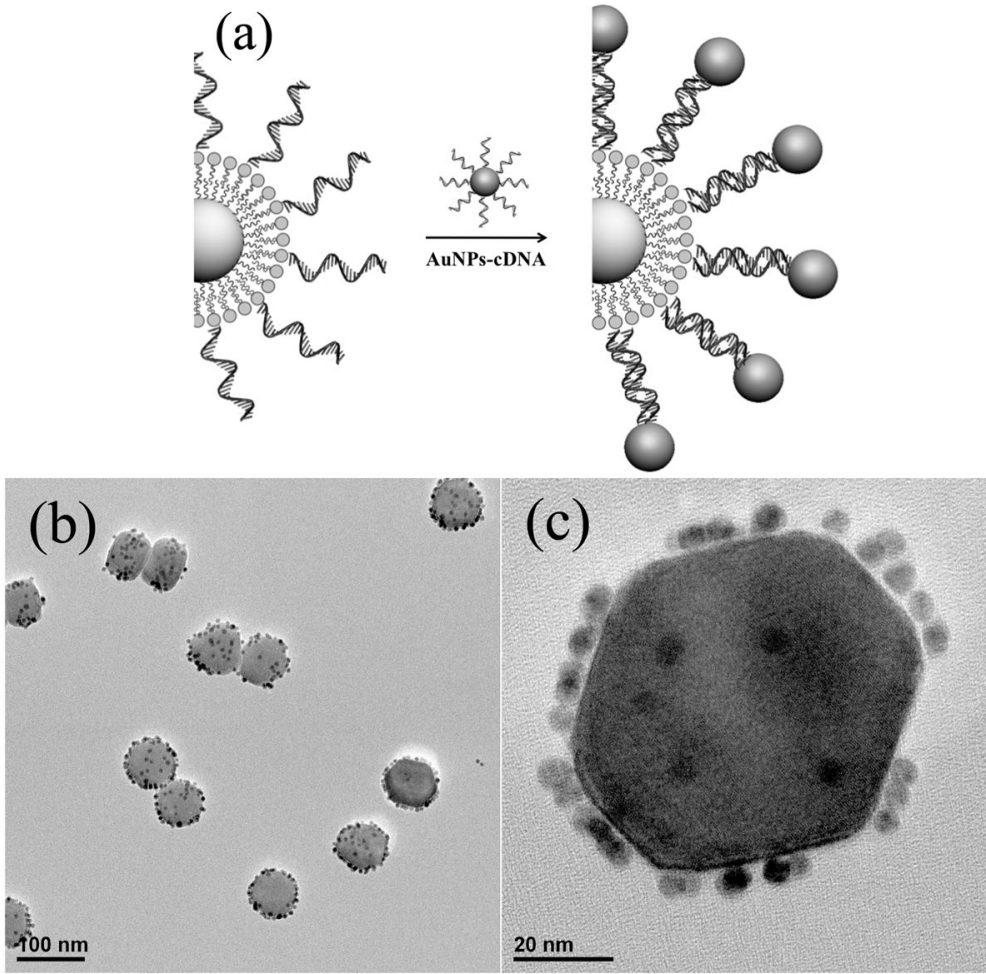

Figure 4.

(a) Schematic illustration and (b, c) TEM images of bioinspired Lipo-UCNP-AuNPs nanoassemblies directed by DNA. 

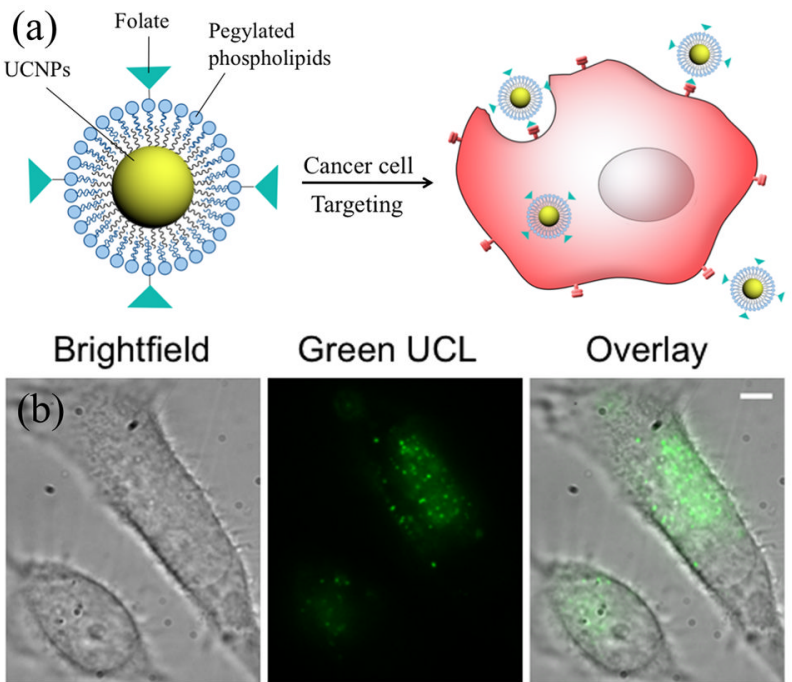

Overlay
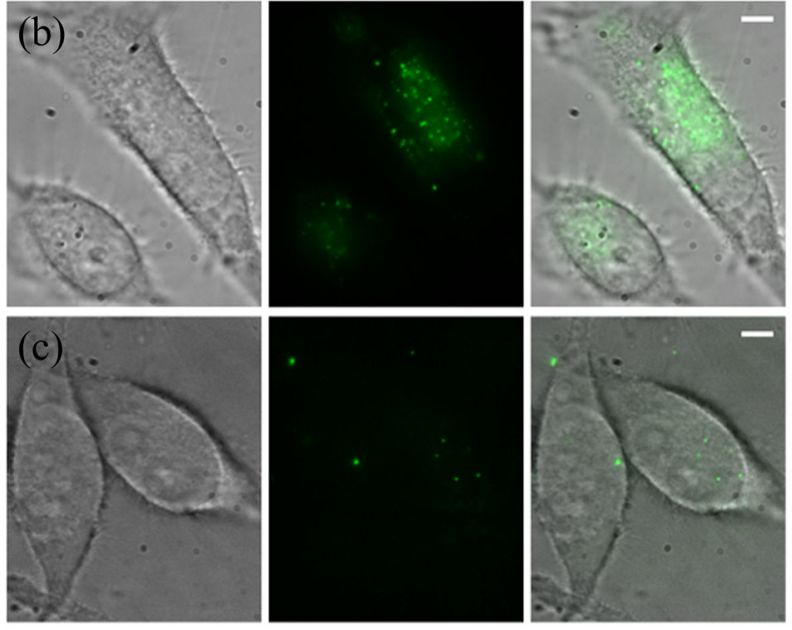

Figure 5.

(a) Schematic illustration of the targeted imaging of cancer cells with Lipo-UCNPs-FA. Luminescence microscopy images of HeLa cells treated with (b) Lipo-UCNPs-FA and (c) Lipo-UCNPs without folate ligand. For UCNPs images, $\lambda_{\mathrm{ex}}=980 \mathrm{~nm}$ and emission were collected in the range $\lambda=510-560 \mathrm{~nm}$. Scale bar $=5 \mu \mathrm{m}$. 